\title{
PONTOS NOTÁVEIS DO TRIÂNGULO: UM ESTUDO ATRAVÉS DA RESOLUÇÃO DE PROBLEMAS
}

\author{
HIGHLIGHTS OF THE TRIANGLE: A STUDY THROUGH PROBLEM \\ SOLVING
}

\author{
Sandra Iris Naveiro Galera' \\ Paulo César Oliveira ${ }^{2}$
}

\begin{abstract}
RESUMO: Este relato de pesquisa envolveu a formulação e resolução de três tarefas com o propósito de promover o estudo do circuncentro, um dos pontos notáveis do triângulo. Este estudo foi motivado a partir das lacunas encontradas na análise documental do Currículo do Estado de São Paulo (SÃO PAULO, 2012) e os respectivos materiais de apoio. Na perspectiva de uma metodologia qualitativa com base no referencial Ensino-Aprendizagem-Avaliação através da Resolução de Problemas, analisamos a produção escrita de 24 estudantes do $9^{\circ}$ ano do Ensino Fundamental envolvidos na resolução de atividades matemáticas. Como resultados de pesquisa, revelamos pontos positivos e pontos de melhoria quanto ao estudo das propriedades do circuncentro através da Resolução de Problemas.
\end{abstract}

Palavras-chave: Formulação de problemas. Pontos notáveis no triângulo. Construções geométricas.

\begin{abstract}
The research report involves the formulation and resolution of three tasks with the purpose of promoting the study of the circumcenter, one of the notable points of the triangle. This study was motivated by the gaps found in the documentary analysis of the Curriculum of the State of São Paulo (SÃO PAULO, 2012) and the respective support materials. In the perspective of a qualitative methodology based on the TeachingLearning-Assessment through Problem Solving framework, we analyzed the written production of 24 students from the 9th grade of elementary school involved in this mathematical activity. As research results, we reveal positive points and points of improvement regarding the study of circumcenter properties through Problem Solving.
\end{abstract}

KEYWORDS: Problem formulation. Notable points in the triangle. Geometric constructions.

\section{Introdução}

O relato de pesquisa com foco no estudo do conceito e aplicabilidade do circuncentro como um dos pontos notáveis de um triângulo faz parte de uma dissertação de Mestrado Profissional em Matemática em Rede Nacional - PROFMAT (GALERA, 2018), desenvolvida pela primeira autora no âmbito do Grupo de Estudos e Planejamento de Aulas de Matemática (GEPLAM) da UFSCar. A linha de pesquisa na qual foi concebido e

\footnotetext{
1 Universidade Federal de São Carlos. E-mail: sandranave@hotmail.com

https://orcid.org/0000-0003-4493-6700

2 Universidade Federal de São Carlos. E-mail: paulooliveira@ufscar.br

(1) https://orcid.org/0000-0003-2514-904X

- Informações completas da obra no final do artigo
} 


\section{ENSIN@UFMS 2021}

ISSN 2525-7056

desenvolvido essa investigação denomina-se "Conteúdo e experimentação para o ensino da matemática" cujo objetivo é planejar e analisar contextos de aulas de matemáticas norteadas por investigações matemáticas, resolução e formulação de problemas ou utilização de materiais didáticos.

As informações geradas pelo objeto de estudo, tiveram a análise pautada na metodologia de Ensino-Aprendizagem-Avaliação através da Resolução de Problemas. Para Onuchic (1999) a perspectiva metodológica através da Resolução de Problemas destaca um processo pelo qual será construído saberes, a medida em que o professor promove situações escolares para o aluno desenvolver atividades matemáticas em sala de aula de maneira gradual, permitindo vislumbrar, durante sua resolução, novos caminhos para aquisição de habilidades e aprendizagens.

A motivação pelo objeto de conhecimento "pontos notáveis de um triângulo" decorreu da análise documental do Currículo do Estado de São Paulo (SÃO PAULO, 2012) e das Situações de Aprendizagem do Caderno do Professor para anos finais do Ensino Fundamental, cujos resultados revelaram lacunas no ensino de geometria. O Caderno do Professor é um material complementar ao currículo oficial de São Paulo, no qual contém orientações didático-pedagógicas por meio de oito Situações de Aprendizagem em cada um dos seus volumes semestrais, destinados aos anos finais do Ensino Fundamental e às séries que compõem o Ensino Médio.

\section{Conceitos geométricos no Currículo do Estado de São Paulo}

A abordagem dos objetos de conhecimento na Matemática está organizada no Currículo do Estado de São Paulo (SÃO PAULO, 2012) em três blocos temáticos relacionados entre si: Números, Geometria e Relações.

O bloco Geometria se baseia na percepção das formas e as relações entre os elementos das figuras planas e espaciais; na construção e na representação das formas geométricas existentes ou abstratas, e na concepção do espaço a compreensão do mundo físico (SÃO PAULO, 2012).

Sobre o processo de ensino-aprendizagem no bloco Geometria podemos destacar que a preocupação inicial, no Ensino Fundamental (especificamente no $6^{\circ}$ e $7^{\circ}$ ano) é trazer o estudo das formas planas e espaciais para situações concretas. Já a ênfase na 
construção de raciocínios lógicos, de deduções simples de resultados a partir de outros anteriormente conhecidos poderá ser a tônica dos trabalhos no $8^{\circ}$ e $9^{\circ}$ ano.

Em relação à Geometria, no decorrer de todos os anos do Ensino Fundamental e Médio, o documento enfatiza:

Consideramos que a Geometria deve ser tratada, ao longo de todos os anos, em abordagem espiralada, o que significa dizer que os grandes temas podem aparecer tanto nas séries/anos do Ensino Fundamental quanto nas do Ensino Médio, sendo a diferença a escala do tratamento dada ao tema. Por exemplo, o número irracional $\pi$, associado aos cálculos da circunferência e do círculo, pode e deve ser apresentado nos cursos de geometria elementar, assim como deve ser trabalhado no Ensino Médio, desta vez em contextos associados à Trigonometria, ao estudo dos corpos redondos e aos conjuntos numéricos. (SÃO PAULO, 2012, p.41)

O desenvolvimento dos objetos de conhecimento geométrico se faz com base em quatro faces inter-relacionadas: percepção, a concepção, a construção e a representação.

A percepção refere-se à observação e caracterização das formas presentes no mundo ao nosso redor e à manipulação de objetos concretos. Frente ao aprendizado de geometria é a face que ocorre por meio de atividades empíricas, ou seja, apoia-se em experiências vividas e observações das coisas. Na fase empírica desta pesquisa, propomos a resolução de um problema que envolveu a localização das residências dos alunos através de mapas, mais especificamente, com o auxílio do Google Maps.

A construção remete-se à produção de materiais a serem manipulados tal qual a elaboração de objetos em sentido físico. Na resolução de um dos problemas propostos, incentivamos o uso de canudos e barbantes como materiais manipulativos na atividade matemática.

A representação refere-se à reprodução através de desenhos percebidos ou construídos. Na resolução dos problemas propostos incluímos a utilização de instrumentos do desenho geométrico como régua e compasso, para o desenvolvimento da atividade matemática dos alunos.

A concepção traz a busca do conhecimento geométrico e a organização dos conceitos através do raciocínio lógico-dedutivo e da teoria: sistematização do conhecimento geométrico; predomínio das definições formais; presença das propriedades, proposições e demonstrações. Foi entendido nesse processo de investigação que as correlações entre as faces percepção, construção e representação, emergiu a concepção geométrica em questão. 
Com base nos Cadernos do Professor para os anos finais do Ensino Fundamental foram analisadas as orientações didático-pedagógicas estabelecidas para o estudo de triângulos. Como o problema de pesquisa implica em abordar propriedades dos triângulos desde as possibilidades para sua construção (desigualdade triangular) bem como a intersecção das mediatrizes (circuncentro), identificamos no Quadro 1 as Situações de Aprendizagem correlacionadas ao estudo dos triângulos:

Quadro 1: O tratamento escolar para triângulos

\begin{tabular}{|c|c|c|c|}
\hline $\begin{array}{l}\text { Caderno do } \\
\text { Aluno }\end{array}$ & Situação de Aprendizagem & Sessão & Tarefas/Etapas \\
\hline $\begin{array}{c}6^{\circ} \text { ano, volume } \\
1\end{array}$ & $\begin{array}{l}\text { Na medida certa: dos naturais } \\
\text { às frações }\end{array}$ & Você aprendeu? & 1 \\
\hline \multirow{3}{*}{$\begin{array}{c}6^{\circ} \text { ano, volume } \\
2\end{array}$} & \multirow{3}{*}{$\begin{array}{l}\text { Definir e Classificar } \\
\text { experimentando }\end{array}$} & Atividade Diagnóstica. & 1,2 \\
\hline & & Lição de casa & 3 \\
\hline & & Você aprendeu? & 4,5 e 6 \\
\hline $\begin{array}{c}6^{\circ} \text { ano, volume } \\
2\end{array}$ & $\begin{array}{c}\text { Geometria e frações com } \\
\text { Geoplano e malhas } \\
\text { quadriculadas }\end{array}$ & Você aprendeu? & 3 \\
\hline \multirow{2}{*}{$\begin{array}{c}7^{\circ} \text { ano, volume } \\
1\end{array}$} & \multirow{2}{*}{ A Geometria dos Ângulos } & Você aprendeu? & 2 a 6 \\
\hline & & Lição de casa & 12 \\
\hline $\begin{array}{c}8^{\circ} \text { ano, volume } \\
2\end{array}$ & $\begin{array}{c}\text { Teorema de Tales: A } \\
\text { proporcionalidade na } \\
\text { Geometria }\end{array}$ & Você aprendeu? & 1,2 e 4 \\
\hline $\begin{array}{c}8^{\circ} \text { ano, volume } \\
2\end{array}$ & $\begin{array}{l}\text { Padrões Numéricos e } \\
\text { Geométricos }\end{array}$ & Pesquisa de campo & Única \\
\hline
\end{tabular}

Fonte: Elaborado pelos autores

Na sequência apresenta-se a abordagem dada ao estudo de triângulos nas diversas tarefas contidas nas Situações de Aprendizagem citadas no Quadro 1.

\section{Na medida certa: dos naturais às frações - As frações no Tangram}

A terceira Situação de Aprendizagem apresentada no Caderno do Professor, 6ำ ano, volume I, abordou a confecção do Tangram composto por cinco triângulos, um quadrado e um paralelogramo, através de dobraduras e recortes.

Três faces do aprendizado de geometria (construção, percepção e concepção) são trabalhadas concomitantemente: ao passo que a construção do Tangram é realizada através da manipulação por dobraduras o aluno percebe sua conexão com formas a sua volta e concebe o significado de unidade de medida. 
As competências e habilidades a serem alcançadas com essa atividade são: "desenvolver a ideia de que medir significa comparar grandezas de mesma natureza; ampliar a noção de número por meio de situações em que a grandeza tomada como unidade não cabe um número exato de vezes na grandeza a ser medida". (SÃO PAULO, Caderno do Professor, 6ำ ano, v.1, 2014-2017, p.38)

Neste sentido, o triângulo retângulo é utilizado como unidade de medida de acordo com o que se pretende atingir com essa tarefa, desconsiderando sua definição, mas promovendo sua importância na construção do conteúdo.

\section{Definir e Classificar experimentando - Atividade Diagnóstica.}

Trata-se da primeira Situação Aprendizagem do Caderno do Professor para o 6o ano do Ensino Fundamental, volume 2. São disponibilizadas um conjunto de formas poligonais e não poligonais com o objetivo de que os alunos identifiquem as diferenças e semelhanças entre figuras. Posteriormente, há uma tarefa na qual os alunos são estimulados a falar sobre uma característica de figura poligonal ou não poligonal, para que os demais colegas identifiquem as figuras correspondentes.

O propósito quanto ao aprendizado de Geometria é qualificar o vocabulário geométrico dos alunos no processo de identificação e caracterização das figuras planas. A face de aprendizado geométrico da concepção se faz através das etapas que conduzem o aluno a definir e conceituar triângulos e outras formas (polígonos, polígonos convexos, quadriláteros, ângulos) de forma inter-relacionada à face da representação e construção através de seus esboços. A percepção permeia todo o processo quando intuitivamente 0 aluno associa as figuras construídas a outras já concebidas por ele.

$\mathrm{Na}$ discussão quanto às características dos quadriláteros notáveis, observamos a ausência de qualificar o losango; um quadrilátero importante em construções geométricas envolvendo a mediatriz. Interpretamos que a apresentação das tarefas no referido Caderno do Professor envolve o objeto de conhecimento "triângulo", o qual surge da necessidade de identificação das características das formas poligonais (figuras formadas por segmentos de retas, fechadas, planas e com ângulos) e suas diferenças das demais figuras geométricas que possuem formas arredondadas, por exemplo. 


\section{Geometria e frações com Geoplano e malhas quadriculadas}

O tema é abordado na terceira Situação de Aprendizagem, no Caderno do Professor, $6^{\circ}$ ano, volume 2. Com o auxílio dos materiais didáticos (Geoplano ou malha quadriculada), propõe-se ao aluno a construção de quadriláteros convexos e não convexos e diferentes triângulos.

O Geoplano é um material muito útil para o ensino da geometria plana mais precisamente o estudo das formas poligonais. É confeccionado a partir de uma placa de madeira com pregos cravados em forma de uma malha composta por linhas e colunas. Os elásticos são utilizados para formar as figuras com limites nos pregos (vértices).

Partindo do pressuposto que os conceitos sobre polígonos convexos e não convexos já tenham sido discutidos ou ainda que, possam ser construídos os alunos devem, através da representação, face do aprendizado da geometria, construir as figuras pedidas. Se faz necessária a concepção das classificações dos triângulos quanto aos lados.

Uma abordagem sobre as impossibilidades na construção de um triângulo dados três comprimentos de lados, seria adequado para que os alunos pudessem se deparar com a desigualdade triangular. Reitera-se que frente a situações deste tipo e da percepção da necessidade desta importante propriedade, foi contemplado uma tarefa em nossa pesquisa para abordar da desigualdade triangular.

\section{A Geometria dos Ângulos}

$\mathrm{Na}$ quinta Situação de Aprendizagem do Caderno do Aluno do $7^{\circ}$ ano, volume I, tarefa 1, o tratamento dado aos ângulos, inicia-se com a construção de uma unidade de medida não convencional: o TUTI. Através de dobraduras é proposto aos alunos a divisão de um quadrado em 16 partes iguais. Espera-se que a resolução da tarefa permita ao aluno constatar que a "soma dos ângulos internos de um triângulo é sempre igual a 8 TUTIS" (SÃO PAULO, Caderno do Professor, 7º ano, v.1, 2014-2017, p.45)

Novamente temos uma tarefa envolvendo a construção de um triângulo sem incluir suas impossibilidades. O momento é propício para que o professor formule indagações, tais como: É possível obter um triângulo com dois ângulos de medida 4 TUTIS? É possível construir um triângulo com lados de medidas 5, 2 e 2 ?

Quanto às faces do aprendizado de Geometria é possível encontrar os quatro eixos: a) construção: dobraduras e recortes para obter as medidas TUTIS; 
b) A percepção permeia todo o aprendizado ao relacionar os lados das figuras e associar os TUTIS às medidas angulares;

c) A Concepção diz respeito à apropriação do conceito de ângulo;

d) Representação: quando se dá a medida do ângulo em TUTIS e pede-se para construir o mesmo ou construir o triângulo e medir seus ângulos.

Uma sugestão de melhoria complementar ao que foi proposto nesta Situação de Aprendizagem é uma abordagem sobre as possibilidades de construção de um triângulo de modo a gerar a desigualdade triangular.

\section{Teorema de Tales: A proporcionalidade na Geometria}

Nessa seção são apresentados no Caderno do Professor, 8o ano, volume 2, problemas associados a situações cotidianas como a construção de canteiro para plantar folhagens rasteiras, por exemplo. Foi interpretado que esta situação-problema instiga a face do aprendizado geométrico "percepção" quando menciona o projeto do canteiro triangular, a qual demanda que o aluno associe a figura abstrata a um canteiro. A construção atrelada a "representação" na forma da figura do triângulo, e os segmentos nele traçados levam o aluno a conceber a proporcionalidade entre os segmentos formados.

\section{Padrões Numéricos e Geométricos}

Na sétima Situação de Aprendizagem, Caderno do Professor do 8o ano, volume 2, há uma tarefa interessante instigando os alunos na construção de um triângulo retângulo utilizando um barbante com 13 nós. Na formulação das tarefas para o instrumento de coleta de dados, foi utilizada uma tarefa complementar a essa, considerando o fato de que com os 12 espaços formados pelos nós não podem ser divididos aleatoriamente de forma a se obter uma região triangular. Neste sentido, aproveitou-se este fato para estudar a questão da desigualdade triangular.

Na sequência apresenta-se a abordagem dada ao estudo da circunferência e do losango, devido o interesse desta pesquisa nos pontos notáveis de um triângulo, a partir das construções geométricas com régua e compasso. 


\section{ENSIN@UFMS 2021}

ISSN 2525-7056

\section{O tratamento escolar para circunferências}

O Caderno do Aluno, 6ํano, volume 1, traz na terceira Situação de Aprendizagem, uma tarefa que consiste em medir diâmetros os objetos de algumas figuras. Cada figura possui uma régua graduada em polegadas. Como a unidade de medida polegadas não é convencional; faz-se necessário uma abordagem do seu significado, bem como a comparação com a unidade padrão de comprimento.

Nesse Caderno do Professor não é apresentado a noção conceitual de circunferência, o que pode suscitar questionamentos em sala de aula. O objetivo principal da tarefa é levar o aluno a se deparar com necessidades de fracionamentos da unidade ao medir um objeto.

A concepção como uma das faces do aprendizado em geometria, se faz necessária, no âmbito de se definir o conceito de diâmetro. Já a percepção com o fato de se relacionar o diâmetro com outras referências do cotidiano: diâmetro de uma cesta de basquete ou pneu de bicicleta, por exemplo.

\section{O tratamento escolar para losangos}

No Caderno do Professor, os losangos são apresentados apenas na forma de 'pipa' e isto pode comprometer a aprendizagem, dado o pressuposto do aluno associar o objeto losango diretamente à representação figural da 'pipa'. Conceitualmente, "losango é um paralelogramo equilátero, isto é, com lados congruentes". (SÃO PAULO, Caderno do Professor, 6을, ano, 2, 2014-2017, p71).

A abordagem da área do losango é determinada de duas formas diferentes. Por um lado, a partir de sua classificação como paralelogramo e, portanto, sua área é equivalente a área do paralelogramo; por outro lado, por decomposição do losango a partir de suas diagonais em triângulos congruentes e a composição de um retângulo equivalente ao losango inicial. A segunda maneira nos permite abordar o conceito das diagonais do losango e suas características.

A face percepção do aprendizado geométrico se faz perante a situação a qual o aluno se depara com a conexão entre as propriedades do losango como paralelogramo; a construção pode ser concretizada a partir de recortes e colagens para decomposição e composição das figuras equivalentes; a representação das áreas por composição e decomposição e a concepção quando os alunos se apropriam das deduções de fórmulas. 
$\mathrm{Na}$ análise documental foi constatado que elementos de geometria como os pontos notáveis de um triângulo não são contemplados na forma de tarefas nas diversas Situações de Aprendizagem contidas nos materiais de apoio do Currículo do Estado de São Paulo (SÃO PAULO, 2012).

\section{Ensino - Aprendizagem - Avaliação através da Resolução de Problemas}

Um grupo de pesquisadores brasileiros, coordenados pela Prof. ${ }^{a} \mathrm{Dr}^{\mathrm{a}}$ Lourdes de la Rosa Onuchic, da UNESP - Rio Claro, SP - GETERP (Grupo de Trabalho e Estudos em Resolução de Problemas), desenvolve suas atividades desde 1992. O grupo é constituído por alunos e ex-alunos do Programa de Pós-Graduação em Educação Matemática que compartilham o interesse por se aprofundar no tema, auxiliar em projetos de pesquisas e aprimorar sua prática docente. Desta forma, o GETERP é um núcleo gerador de atividades que motivam o aperfeiçoamento, a investigação e produção científica na linha de Resolução de Problemas.

O trabalho com Resolução de Problemas em sala de aula é uma atividade coletiva, construída entre professor e alunos, que compartilham suas ideias de forma a colaborar com cada integrante no processo de Ensino - Aprendizagem - Avaliação (ONUCHIC, 1999). As três palavras de forma composta, tem por objetivo expressar uma concepção em que 0 ensino-aprendizagem devem ocorrer de forma simultânea através da mediação do professor e participação efetiva dos alunos na produção de saberes. A Avaliação ocorre durante $\mathrm{o}$ processo de desenvolvimento das atividades matemáticas, articulada às formulações e construções dos alunos.

Para Onuchic (1999, p.215) um problema "é tudo aquilo que não se sabe fazer, mas que se está interessado em resolver" e não é um exercício no qual o aluno aplica uma fórmula de forma quase mecânica ou alguma técnica operatória". Em termos metodológicos, Onuchic e Allevato (2009) sugere um conjunto de 9 etapas para a organização do trabalho do professor em sala de aula, levando em conta que a avaliação, por sua vez, perpassa o desenvolvimento do processo ensino-aprendizagem:

(1) O professor propõe um problema para os estudantes resolverem;

(2) Os estudantes são desafiados a utilizar seus conhecimentos prévios;

(3) Os estudantes formam pequenos grupos;

(4) O professor incentiva os estudantes e realiza a mediação; 
(5) Os estudantes resolvem o problema;

(6) As soluções dos estudantes são apresentadas a todos;

(7) Realiza-se uma plenária discutindo as resoluções desenvolvidas;

(8) Busca-se um consenso dos processos de resolução dos estudantes;

(9) O professor formaliza o conteúdo matemático.

\section{Percurso metodológico da pesquisa}

A proposta metodológica de Ensino-Aprendizagem-Avaliação através da Resolução de Problemas contou com a participação de 24 estudantes de $9^{\circ}$ ano de uma escola do município de Tatuí, envolvidos com atividades matemáticas relacionadas à propriedade do circuncentro no triângulo.

A pesquisa de natureza qualitativa, caracterizou-se por um estudo naturalista ou de campo em função da mediação da professora-pesquisadora com seus alunos no decorrer do desenvolvimento das tarefas propostas (NACARATO et al, 2005). A produção de informações submetida à análise foi obtida via registros escritos das três atividades desenvolvidas pelos alunos em sala de aula, fotos, vídeos e anotações do professorapesquisadora.

Seguindo a prerrogativa do ensino via Resolução de Problemas, na perspectiva de Onuchic e Allevato (2009), apresenta-se informações relevantes às 3 primeiras etapas: formulação das tarefas pela professora-pesquisadora; leitura individual das tarefas pelos alunos e leitura coletiva.

No Quadro 2 sistematizamos os temas envolvidos nas 3 tarefas conjuntamente com os conteúdos abordados:

Quadro 2. Tarefas via Resolução de Problemas

\begin{tabular}{|l|l|}
\hline Tarefa: Tema & \multicolumn{1}{|c|}{ Conteúdos } \\
\hline $\begin{array}{l}\text { Explorando o conceito e as } \\
\text { propriedades da Mediatriz }\end{array}$ & $\begin{array}{l}\text { Ponto Médio, Losango como quadrilátero Notável e suas propriedades, } \\
\text { Circunferência e mediatriz }\end{array}$ \\
\hline $\begin{array}{l}\text { O Circuncentro de um } \\
\text { triângulo e suas propriedades }\end{array}$ & $\begin{array}{l}\text { Triângulos, Desigualdade triangular, Mediatrizes dos lados dos } \\
\text { triângulos, Ponto de Intersecção das mediatrizes (posição relativa à } \\
\text { superfície triangular), Circuncentro e suas propriedades. }\end{array}$ \\
\hline $\begin{array}{l}\text { Aplicação das propriedades } \\
\text { do Circuncentro }\end{array}$ & Circuncentro e suas propriedades \\
\hline
\end{tabular}

Fonte: Elaborado pelos autores. 
No que diz respeito à leitura individual das tarefas, foi um momento oportuno para cada aluno compreender o conteúdo do problema, ou seja, levar o aluno a questionar sobre do que se trata, quais palavras desconhece, entre outras coisas. Por isso foi imprescindível criar um ambiente calmo e silencioso. Sabemos das dificuldades de concentração dos adolescentes nessa faixa etária e, portanto, houve necessidade de dialogar sobre a importância de se manter concentrado na leitura do enunciado dos problemas. Após a leitura individual, os questionamentos já começaram a surgir a respeito dos enunciados. Foi pedido que anotassem as dúvidas para que, no total de 6 grupos formados, fossem discutidas.

A leitura em conjunto não foi muito produtiva, apesar dos alunos serem instruídos quanto ao respeito à leitura do próximo. Percebeu-se que para a interpretação do problema, foi mais eficiente a leitura feita por um membro do grupo e, os demais atentos a ela, anotaram dúvidas para posteriormente discutir. Com relação às deficiências de vocabulário, foi sugerido aos alunos o uso de dicionários e incentivo de pesquisa via internet.

Nas seções seguintes contemplou-se à apresentação do conteúdo e análise do desempenho qualitativo dos alunos em algumas questões que formaram o conjunto das 3 tarefas propostas.

\section{Primeira tarefa}

Essa tarefa foi composta de 4 questões, cujo conteúdo está disposto no Quadro 3:

Quadro 3. Explorando o conceito e as propriedades da Mediatriz.

\begin{tabular}{|c|c|c|}
\hline Conteúdo & Recurso & Objetivo \\
\hline $\begin{array}{l}\text { 1- Ponto médio. } \\
\text { 2-Losango como quadrilátero } \\
\text { notável. } \\
\text { 3-Propriedades do losango. } \\
\text { 4-Construcaão } \\
\text { circunferência. } \\
\text { 5-Mediatrizes e da suas } \\
\text { propriedades. }\end{array}$ & $\begin{array}{l}\text { 1-Materiais de DG } \\
\text { (régua e compasso). } \\
\text { 2-Transferidor. } \\
\text { 3-Canudos. } \\
\text { 4-Dicionário. } \\
\text { 5-Internet }\end{array}$ & $\begin{array}{l}\text { 1-Compreender o significado de ponto médio de } \\
\text { um segmento através de atividades experimentais. } \\
\text { 2-Retomar as características de uma } \\
\text { circunferência através da construção com } \\
\text { compasso, dado seu raio. } \\
\text { 3-Utilizar as propriedades do losango para } \\
\text { construção da mediatriz com régua e compasso. }\end{array}$ \\
\hline
\end{tabular}

Fonte: Elaborado pelos autores

A quarta questão envolveu a construção da mediatriz do segmento $\overline{A B}$, bem como a redação do roteiro para tal procedimento com o uso de régua e compasso. Na Figura 1 destaca-se o protocolo escrito do aluno João (nome fictício): 
Figura 1. Roteiro para construção da mediatriz de um segmento de reta

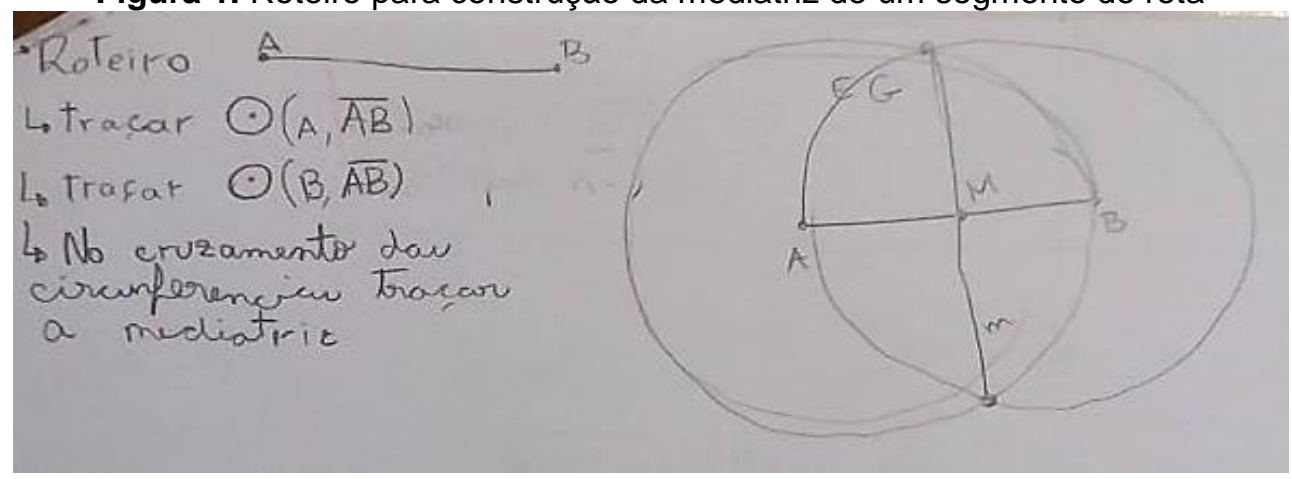

Fonte: Elaborado pelos autores

A produção escrita de João contém uma representação matemática na forma simbólica "traçar $\odot(A, \overline{A B})$ ", cuja referência é uma circunferência de centro $\mathrm{A}$ e raio com medida AB. Na Figura 2 apresenta-se a respectiva construção geométrica de João:

Figura 2. Construção da mediatriz DC

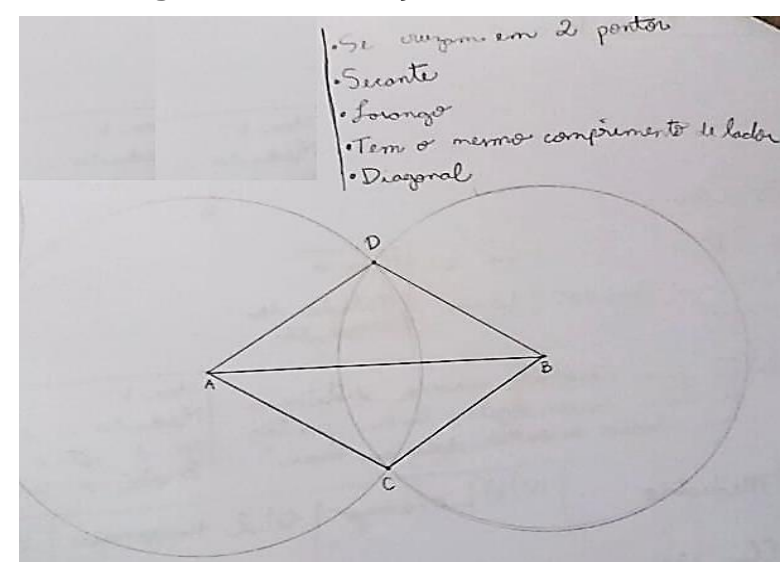

Fonte: Elaborado pelos autores

Ao finalizar essa etapa da primeira tarefa, a professora-pesquisadora apresentou para os alunos na plenária, o protocolo da construção geométrica de João e questionou a ausência da representação da mediatriz do segmento de reta $A B$. A aluna Márcia fez a conexão da mediatriz com a diagonal $C D$ do losango CBDA. A professora-pesquisadora, por sua vez, questionou: "o que podemos observar quanto à posição relativa entre as diagonais de um losango?" Sem dificuldades, vários alunos manifestaram que as diagonais são perpendiculares entre si.

Em síntese, cada face do aprendizado geométrico foi explorada na resolução das questões da primeira tarefa. No Quadro 4, está exposto o registro escrito de atividades geométricas realizadas pelos alunos: 
Quadro 4. Faces do aprendizado geométrico na primeira tarefa

\begin{tabular}{|c|c|}
\hline Faces & Atividade \\
\hline Construção & João construiu a mediatriz do segmento AB com régua e compasso \\
\hline Percepção & Laura relacionou um canudo de plástico com o segmento de reta AB. \\
\hline Concepção & $\begin{array}{c}\text { Através do roteiro exposto na Figura 1, João mostrou que compreendeu } \\
\text { como elaborar as estratégias para a construção geométrica da mediatriz } \\
\text { de AB. }\end{array}$ \\
\hline Representação & João apresentou a representação geométrica da mediatriz através do uso \\
de régua e compasso.
\end{tabular}

Fonte: Elaborado pelos autores

$\mathrm{Na}$ resolução dessa questão, o foco não foi o procedimento realizado com o manuseio da régua e compasso, mas identificar e caracterizar o quadrilátero losango na construção da mediatriz de um segmento de reta.

\section{Segunda Tarefa}

Essa tarefa foi composta de 3 questões, cujo conteúdo está disponível no Quadro 5:

Quadro 5. Circuncentro de um triângulo e suas propriedades.

\begin{tabular}{|c|c|c|}
\hline Conteúdo & Recurso & Objetivo \\
\hline $\begin{array}{l}\text { 1-Triângulos } \\
\text { 2-Desigualdade triangular } \\
\text { 3-Mediatriz relativa aos lados do } \\
\text { triângulo } \\
\text { 4-Ponto de Intersecção das } \\
\text { mediatrizes de um triângulo } \\
\text { 5-Circuncentro e suas } \\
\text { propriedades. }\end{array}$ & $\begin{array}{l}\text { 1-régua e } \\
\text { compasso } \\
\text { 2-dicionário } \\
\text { 3-internet } \\
\text { 4-barbante }\end{array}$ & $\begin{array}{l}\text { 1-Perceber que não são três comprimentos quaisquer } \\
\text { que podem representar os lados de um triângulo e } \\
\text { desta forma conjecturar a propriedade da } \\
\text { desigualdade triangular. } \\
\text { 2-Construir com régua e compasso as mediatrizes dos } \\
\text { lados de um triângulo retângulo, isósceles e escaleno. } \\
\text { 3-Identificar o ponto de intersecção das mediatrizes } \\
\text { como o circuncentro e compreender suas } \\
\text { propriedades. }\end{array}$ \\
\hline
\end{tabular}

Fonte: Elaborado pelos autores

Na sequência há a formulação de cada uma das questões e as respectivas análises com base em algumas produções escritas dos alunos.

A primeira questão contém o seguinte enunciado: Com um pedaço de barbante de aproximadamente $80 \mathrm{~cm}$ de comprimento faça nós igualmente espaçados de forma a se obter 10 espaços. a) Construa com esse barbante um triângulo. Qual é o perímetro desse triângulo? Quais as medidas de seus lados? b) Agora, construa outros triângulos com esse mesmo barbante. Quantos triângulos diferentes você conseguiu descobrir? Registre a medida de seus lados. c) Tente construir um triângulo com lados medindo 6, 2 e 2. O que você observa? (Registre suas hipóteses) d) Com quaisquer medidas podemos formar um triângulo? Registre como pensou. 


\section{ENSIN@UFMS 2021}

ISSN 2525-7056

Após cortar os pedaços de barbante, os alunos distribuídos em grupos com 6 integrantes cada e começaram a trabalhar nos espaçamentos e nós. Alguns questionamentos foram feitos pelos estudantes: quando realizamos os nós, se perdem alguns "pedaços" do comprimento total do barbante, isso tem algum problema, professora? - Os espaços entre os nós não ficarão exatamente do mesmo tamanho.

A professora-pesquisadora retomou o objetivo da primeira questão: construir triângulos cuja unidade de medida é o espaço entre os nós. Assim, os grupos perceberam que havia necessidade de minimizar a diferença dos espaços entre os nós. No entanto, como a tarefa envolveu uma atividade manipulativa, não foi possível conseguir espaços congruentes, conforme ilustração na Figura 3:

Figura 3. Espaços não congruentes entre os nós

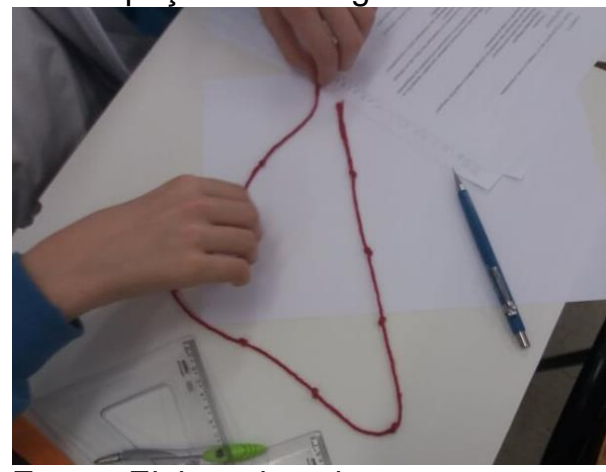

Fonte: Elaborado pelos autores

No decorrer do desenvolvimento da questão, os grupos perceberam imediatamente que o perímetro do triângulo seria aproximadamente $80 \mathrm{~cm}$. Ao tentarem construir triângulos, foi possível notar que determinados casos como no 'item c', não possibilitou a construção. Era desejável que os alunos argumentassem sobre a condição de existência de um triângulo com base na desigualdade triangular. Porém, no registro escrito de vários alunos, foi frequente apenas o argumento de que a manipulação de alguns casos com os lados formados com o barbante não permitiu "fechar" o triângulo.

O protocolo escrito coletivamente pelo terceiro grupo apresenta uma linguagem geométrica próxima ao conteúdo da desigualdade triangular, conforme Figura 4.

$\mathrm{Na}$ resolução do 'item a', os lados foram nomeados de espaços e o triângulo obtido com lados 3, 3, e 4 unidades tem perímetro de 10 unidades. Para o 'item c' a impossibilidade de construir o triângulo com lados medindo 10, 4 e 4 unidades foi justificada pelo fato de que "a medida de dois de seus lados não supera a medida do terceiro" lado. 
Figura 4. Explorando a Desigualdade Triangular

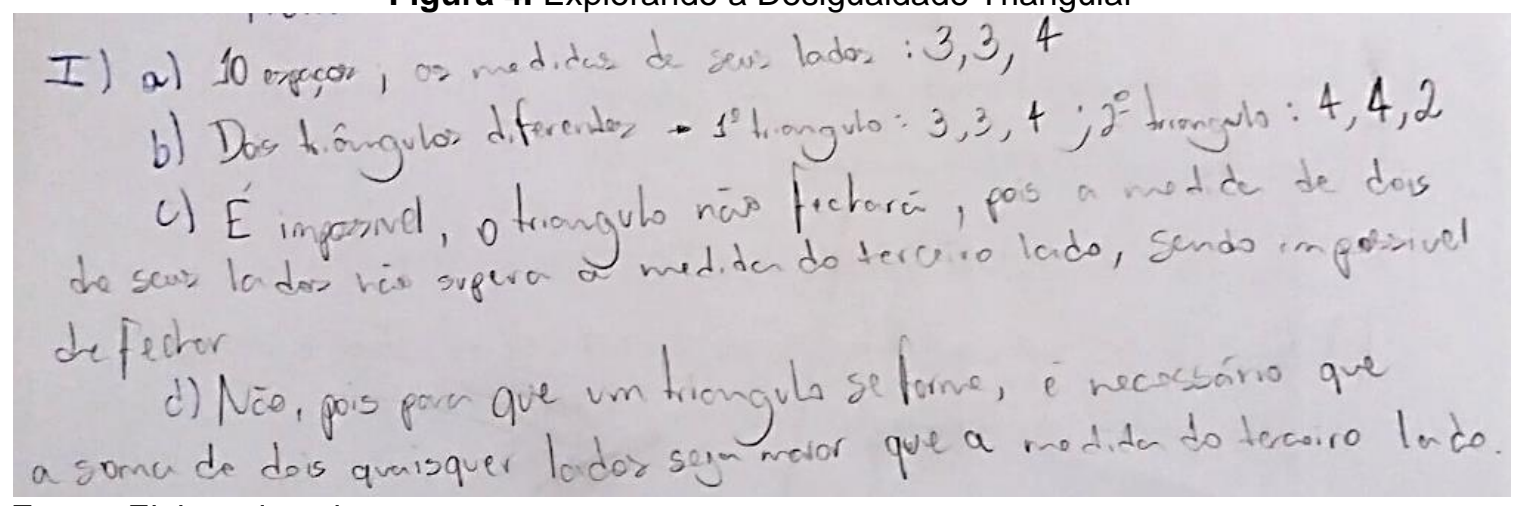

Fonte: Elaborado pelos autores

A segunda questão contém o seguinte enunciado: A propriedade que acabamos de conjecturar é a desigualdade triangular. O próximo desafio consiste em construir triângulos com régua e compasso. Construa com régua um segmento de $8 \mathrm{~cm}$ e nomeie de $\overline{\mathrm{AB}}$. a) Tomando $A B$ como a base de um triângulo equilátero, como você faria para construir os demais lados desse triângulo? Utilize régua e compasso. Nomeie o terceiro vértice de $\mathrm{C}$. b) Escreva um roteiro para construção de um triângulo com régua e compasso. c) Construa triângulos de perímetro $12 \mathrm{~cm}$. d) Quais as possíveis medidas inteiras para os lados desses triângulos? e) Dentre os triângulos construídos no item anterior há um que é um triângulo retângulo. Quais as medidas de seus lados?

Os itens de 'a' a 'c' foram realizados sem muitas dificuldades pelos 6 grupos. A partir do 'item d' os grupos sentiram a necessidade de utilizar a plenária de avaliar se realmente eram 3 possibilidades de triângulos diferentes (Figura 5) com lados formados por números naturais; com o mesmo perímetro $(12 \mathrm{~cm})$.

Figura 5. Triângulos de perímetro $12 \mathrm{~cm}$

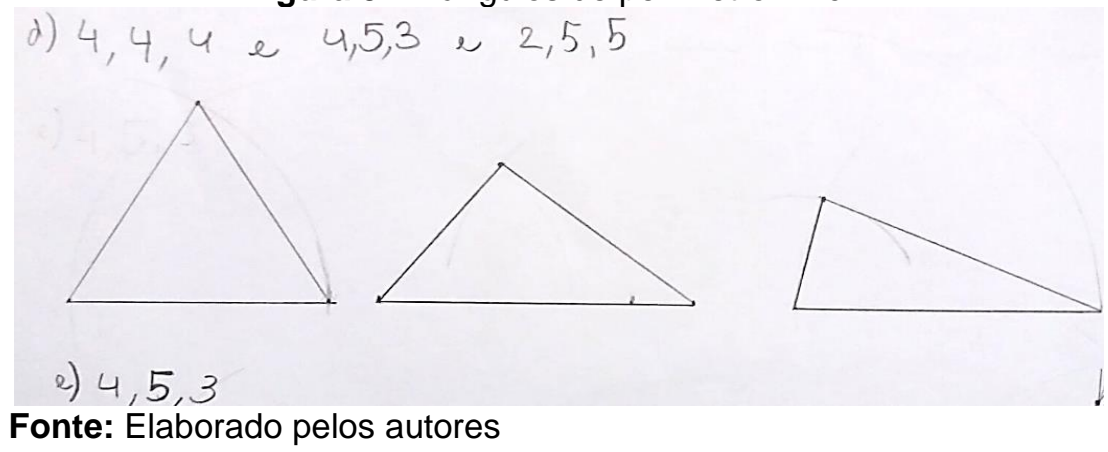

Em relação ao 'item e' a percepção dos alunos quanto ao triângulo retângulo, oscilou entre a construção de lados 4-5-3 e 2-5-5, de acordo com o conteúdo da Figura 5. Alguns 
alunos recorreram ao uso do transferidor ou esquadro como instrumentos de medida para averiguar que o triângulo retângulo é aquele com medidas de lados 4-5-3.

Por fim, a terceira questão contém o enunciado: Na primeira tarefa aprendemos o que é uma mediatriz. Agora vamos trabalhar com as mediatrizes dos lados de um triângulo. a) Construa três triângulos. (retângulo, acutângulo e obtusângulo). Não esqueça de nomear seus vértices; b) Construa em cada um deles as mediatrizes de seus lados; c) O que você observa quanto as mediatrizes em cada um dos triângulos? O que há em comum nos três triângulos quanto às mediatrizes? d) Nomeie os pontos de intersecção de C1, C2 e C3, respectivamente. $\mathrm{O}$ que acontece com os pontos de intersecção das mediatrizes nos três triângulos construídos quanto a sua localização em relação à superfície triangular? e) Com o centro do compasso no ponto de intersecção das mediatrizes e abertura em um dos vértices, trace uma circunferência em cada uma das três construções. O que você observa? f) Como se chama o ponto de intersecção das mediatrizes de um triângulo? Escreva suas características.

Os alunos não tiveram grandes problemas para construir os triângulos e as mediatrizes relativas a cada lado, mas foi observado o quão os estudantes resistiram a apagar e refazer a construção geométrica, mediante avaliação da professora-pesquisadora. A resistência por parte dos alunos não pela falta do conhecimento e sim por desinteressarse em fazer todo o processo novamente. Como mediadores do processo ensinoaprendizagem, foi feita a avaliação contínua do desenvolvimento das atividades dos alunos.

Em relação ao 'item c' houve dúvidas no conteúdo do enunciado. Após discutir em plenária, os alunos conseguiram desenvolver a atividade matemática recorrente. Parte dos alunos responderam que as mediatrizes relativas aos lados do triângulo se cruzavam em um único ponto e um dos grupos respondeu que essas mediatrizes formaram retas concorrentes.

No 'item f' os alunos recorreram à internet para pesquisar o nome do ponto de intersecção das mediatrizes construídas a partir dos lados de um triângulo; o circuncentro. Era esperado inicialmente que os alunos chegassem a conclusão que o circuncentro equidista dos vértices do triângulo, já que é o centro da circunferência circunscrita, porém não tiveram dificuldades de entender após tal fato ser discutido por todos em plenária.

Apresentou-se na Figura 5 a construção das circunferências circunscritas aos triângulos realizadas pelo terceiro grupo, tendo como redatora a aluna Pietra: 
Figura 6. Respostas da terceira questão da segunda tarefa
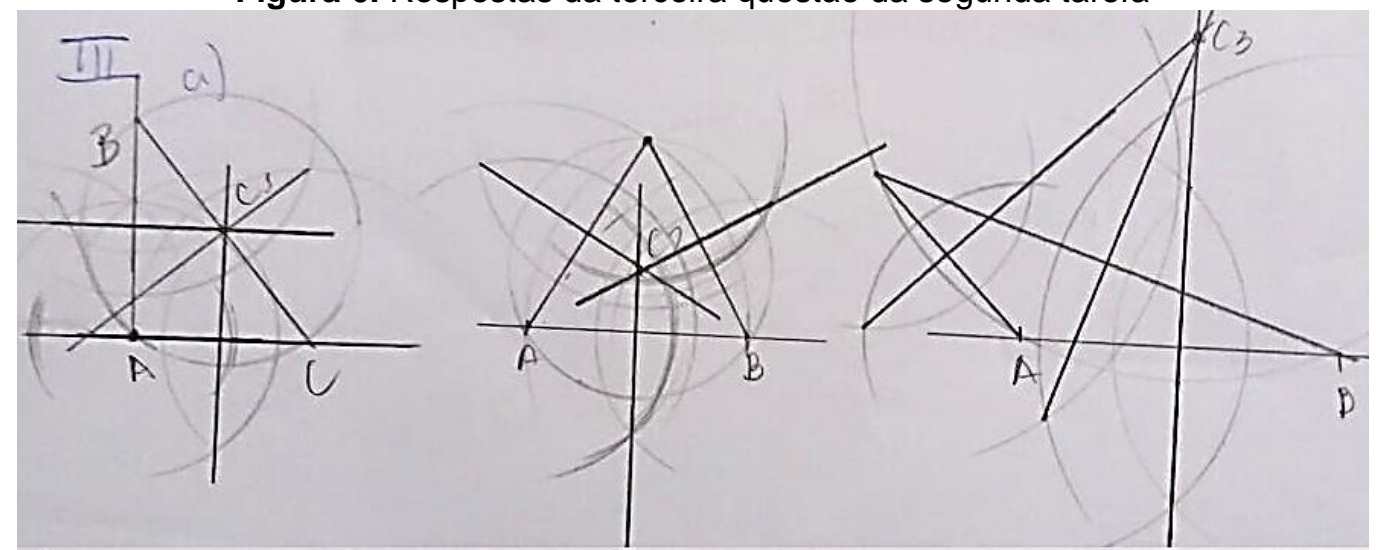

b)

c) Elas se encartion en um parto, o circuncedio

d) Elos formern a circureentro

e) Que os triangulos estas incritos na ciranterencia

f) Chama-se cirancentro, suas caracteristicez säo encontrar

as tides pontos do triangulo sob um namo raio.

Fonte: Elaborado pelos autores

O grupo representado por Pietra destacou na caracterização do circuncentro a medida do raio, com referência aos pontos C1, C2 e C3; centro de cada uma das circunferências circunscritas aos triângulos construídos.

Em síntese, o Quadro 6 contém o que foi explorado das faces do aprendizado geométrico na resolução das 3 questões pertinentes à segunda tarefa:

Quadro 6. Faces do aprendizado geométrico para a segunda tarefa

\begin{tabular}{|l|l|}
\hline Faces & Atividade \\
\hline Construção & $\begin{array}{l}\text { Com } 9 \text { nós, o grupo da Pietra conseguiu dividir o barbante em } 10 \text { espaços com medidas } \\
\text { de comprimento muito próximas e construíram um triângulo de espaços de 3-3-4. }\end{array}$ \\
\hline Percepção & $\begin{array}{l}\text { Pedro constatou que com os nós era possível identificar vértices de um triângulo e, } \\
\text { portanto, construi-lo. }\end{array}$ \\
\hline Concepção & $\begin{array}{l}\text { Pietra escreveu que para formar um triângulo é necessário que a soma de dois } \\
\text { quaisquer lados seja maior que a medida do terceiro lado. }\end{array}$ \\
\hline Representação & $\begin{array}{l}\text { Pedro construiu corretamente as mediatrizes do triângulo acutângulo com régua e } \\
\text { compasso. }\end{array}$ \\
\hline
\end{tabular}

Fonte: Elaborado pelos autores

O conteúdo das duas tarefas na perspectiva metodológica do Ensino-AprendizagemAvaliação através da Resolução de Problemas teve por objetivo abordar com os alunos a 
conceituação da mediatriz de um segmento de reta $\overline{A B}$ como um conjunto de pontos do plano que equidistam das extremidades deste segmento $\overline{A B}$. Dado que a mediatriz de um segmento de reta $\overline{A B}$ satisfaz a propriedade de uma reta perpendicular a este segmento e que intercepta o seu ponto médio, então podemos afirmar que a mediatriz é um lugar geométrico.

Formalmente, de acordo com Dutenhefner; Cadar (2015, p.74), o "lugar geométrico é um conjunto de pontos caracterizado por uma propriedade. Deste modo, uma figura descrita por uma propriedade é um lugar geométrico se: (a) Todos os pontos da figura têm a propriedade; (b) Somente os pontos da figura têm a propriedade".

O estudo da mediatriz como lugar geométrico permitiu-nos abordar o circuncentro como um ponto notável do triângulo, obtido pela intersecção das mediatrizes dos lados de um triângulo. O circuncentro, por sua vez, satisfaz a propriedade de representar o raio da circunferência circunscrita ao triângulo, ou seja, uma circunferência que intercepta os vértices do triângulo.

Neste sentido, na próxima seção o leitor encontrará uma situação de contexto escolar que estabelece conexões entre as propriedades da circunferência circunscrita ao triângulo dado e a solução de uma tarefa proposta através da Resolução de Problemas.

\section{Terceira Tarefa}

A professora-pesquisadora propôs aos seus alunos a seguinte formulação de problema: você e dois amigos de grupo resolveram marcar um passeio. Pensaram em marcar o encontro de saída em um lugar que seja equidistante das casas de cada um. Como vocês devem proceder para descobrir esse lugar?

Esta resolução de problema foi desenvolvida com o auxílio de computadores disponibilizados na sala de informática da unidade escolar. A professora-pesquisadora propôs aos alunos que formassem trios para a utilização do Google Maps. A ferramenta Google Maps é um serviço de pesquisa e visualização de mapas e imagens de satélite da Terra gratuito na web e, através dele foi solicitado que cada grupo localizasse as suas residências e marcasse com as ferramentas do próprio aplicativo a localização das três moradias, na forma de 3 pontos.

Na sequência, a professora-pesquisadora solicitou a utilização do editor Paint que compõe os programas do sistema operacional Windows. O objetivo era que os trios de 
alunos selecionassem a imagem, copiassem e a colassem no editor gráfico Paint. Com pequenas edições na imagem, os alunos ligariam os três pontos que representam as moradias com segmentos de retas para formar um triângulo, cujas imagens foram salvas e impressas, conforme modelo na Figura 7:

Figura 7: Modelo gerado a partir do Google Maps da cidade de Tatuí [sp:

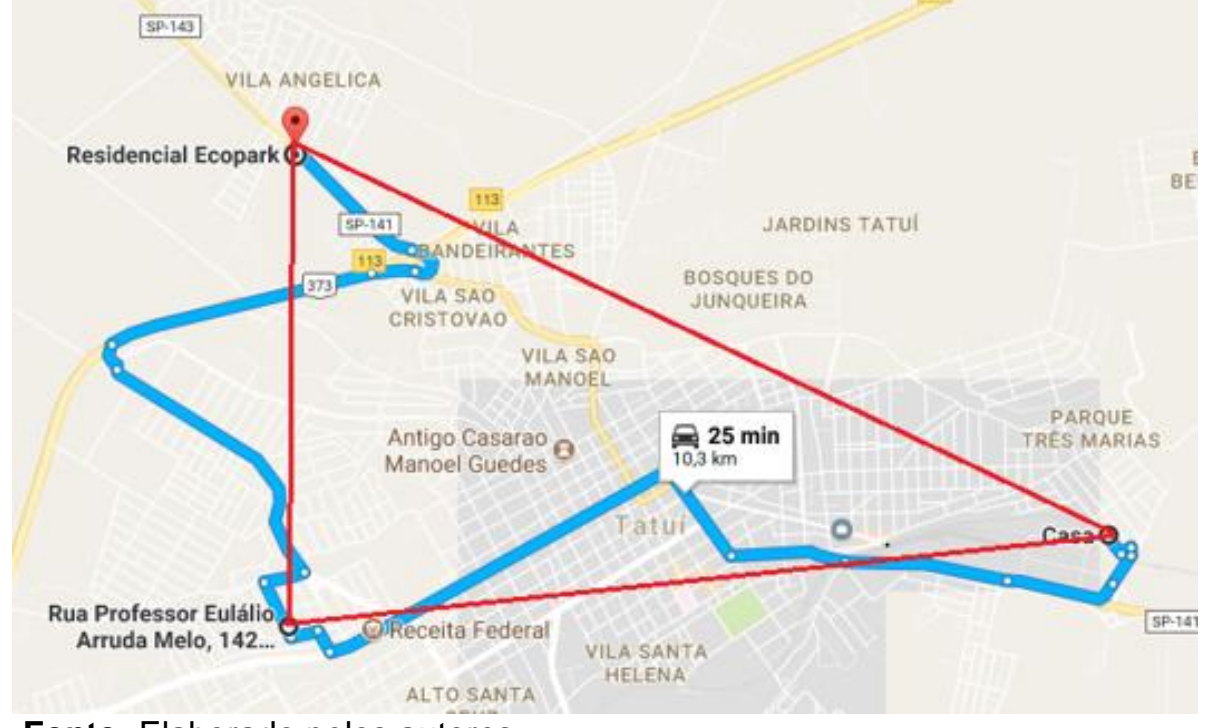

Fonte: Elaborado pelos autores

Com uma postura mediadora em relação aos alunos, a professora-pesquisadora redigiu na lousa as seguintes questões para reflexão: que características devem ter o ponto no mapa que indicará o local do encontro? O que representam as residências no triângulo formado?

As discussões iniciais em trios e depois socializadas em plenária permitiu os alunos compreenderem que a estratégia para a solução da tarefa através da Resolução de Problemas perpassa pelo circuncentro do triângulo dado. Uma questão adicional foi formulada pela professora-pesquisadora: esse lugar que representa o circuncentro no mapa é conveniente para se marcar um encontro?

O conteúdo da Figura 8 e 9 contempla a construção geométrica do circuncentro a partir dos protocolos produzidos pelos grupos 5 e 6 representados, respectivamente, pelos alunos redatores Lívia e Enzo: 
Figura 8: Circuncentro obtido pelo grupo 5

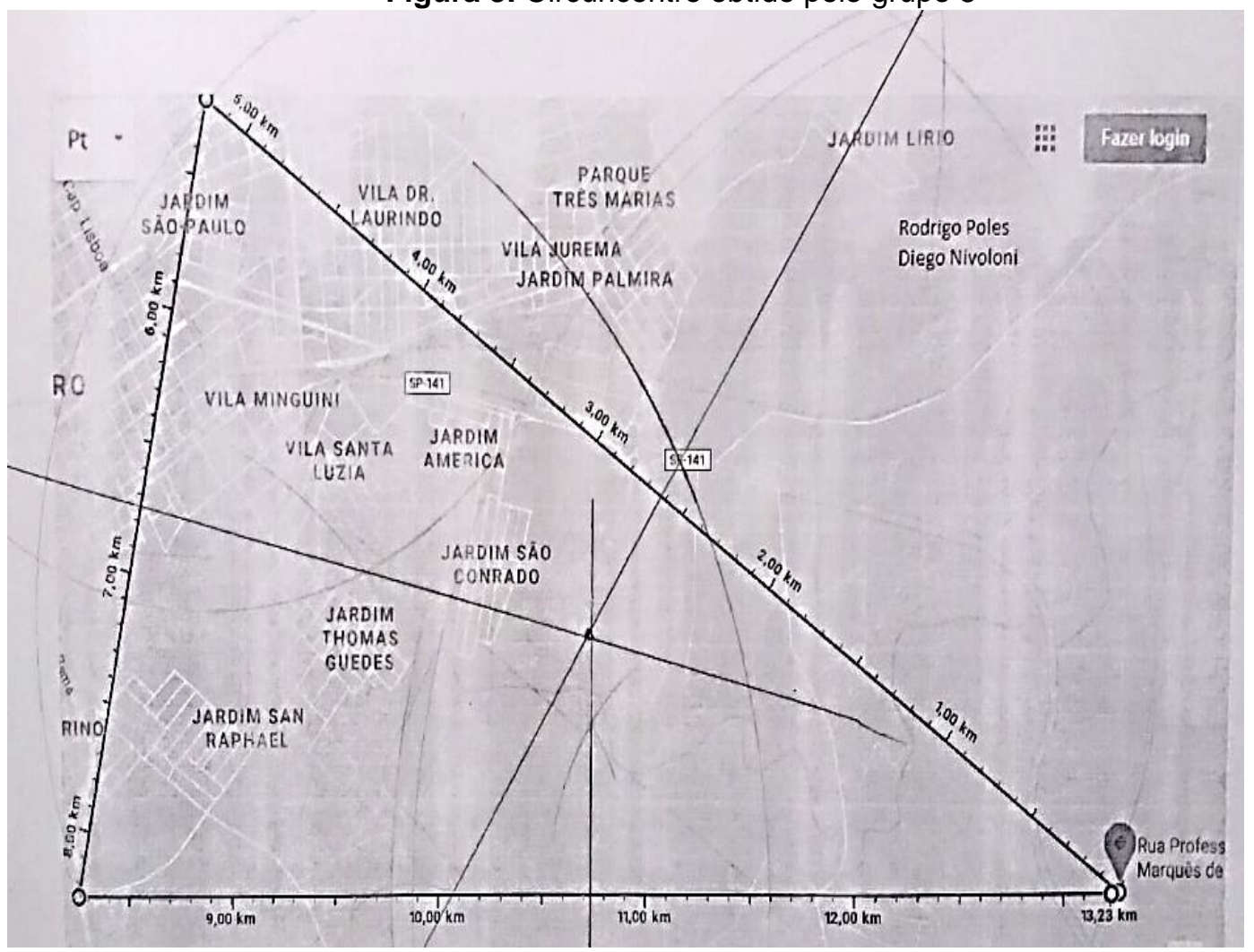

Fonte: Elaborado pelos autores

Figura 9: Circuncentro obtido pelo grupo 6

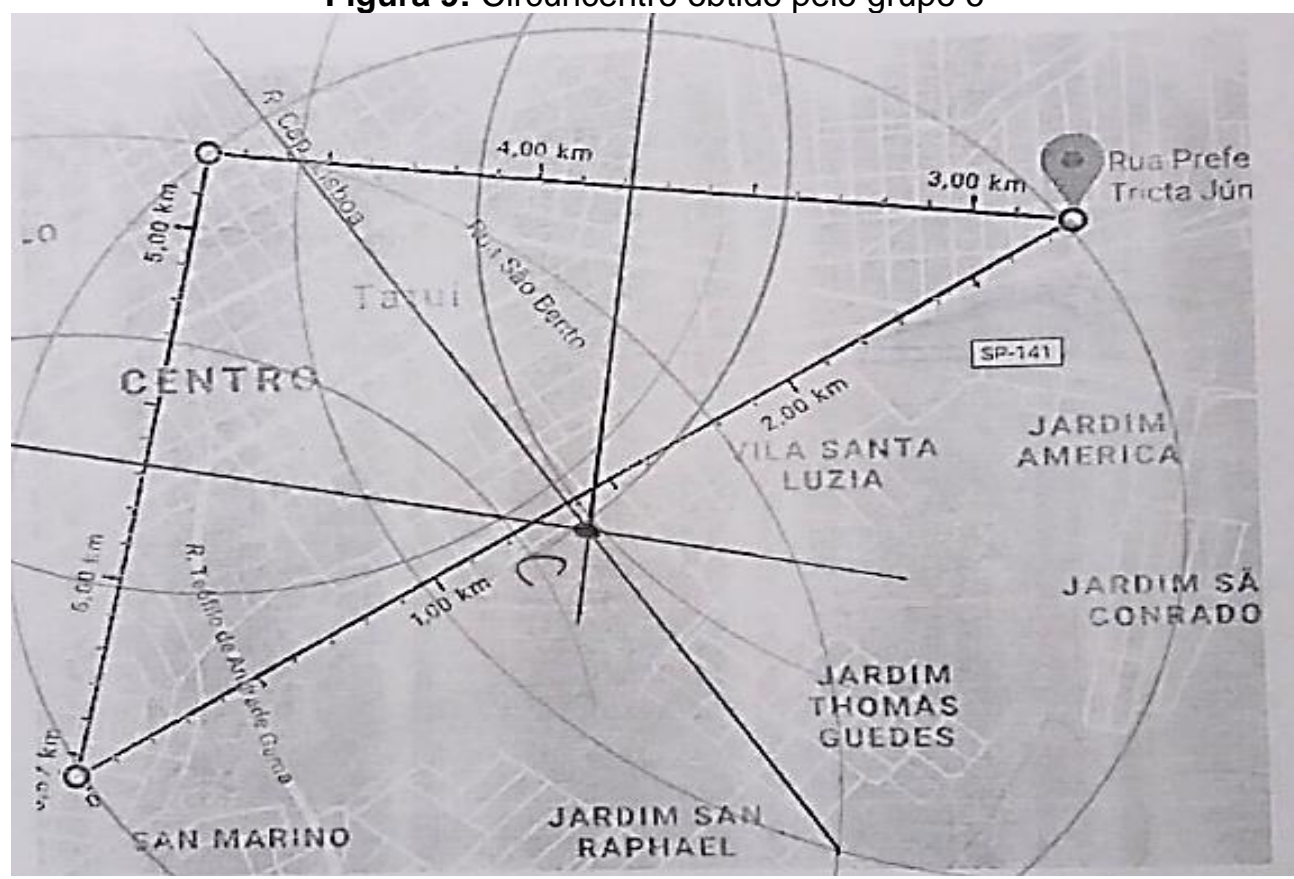

Fonte: Elaborado pelos autores

Em ambos os grupos, a avaliação proposta pela professora-pesquisadora quanto à conveniência ou não de marcar um encontro a partir do circuncentro obtido no mapa, foi 
considerada pelos dois grupos como conveniente, por haver locais públicos próximos ao ponto destacado no mapa.

No Quadro 7 descrevemos as faces do aprendizado geométrico relativo aos grupos 5 e 6 :

Quadro 7. Faces do aprendizado geométrico na terceira tarefa

\begin{tabular}{|l|l|}
\hline \multicolumn{1}{|c|}{ Faces } & \multicolumn{1}{c|}{ Atividade } \\
\hline Construção & $\begin{array}{l}\text { Os Grupos 5 e } 6 \text { produziram seus triângulos com o auxílio de recursos computacionais } \\
\text { e com o auxílio da régua e compasso, construíram o circuncentro do triângulo. }\end{array}$ \\
\hline Percepção & $\begin{array}{l}\text { Os Grupos 5 e 6 perceberam que a construção das mediatrizes e identificação do } \\
\text { circuncentro permitiria obter o ponto equidistante das três moradias. }\end{array}$ \\
\hline Concepção & $\begin{array}{l}\text { Os dois grupos se apropriaram das propriedades do circuncentro quando realizaram } \\
\text { as construções de forma adequada ou através das discussões na plenária }\end{array}$ \\
\hline Representação & $\begin{array}{l}\text { O grupo do Enzo construiu com régua e compasso as mediatrizes do triângulo e, } \\
\text { assim, encontrou corretamente o ponto de intersecção. Como o triângulo obtido a partir } \\
\text { das suas residências (vértices) foi obtusângulo, o circuncentro ficou externo à } \\
\text { superfície triangular. No caso do grupo da Lívia, os procedimentos de construção } \\
\text { geométrica foram semelhantes. No entanto, } \\
\text { como o triângulo foi acutângulo, o circuncentro ficou interno à superfície triangular. }\end{array}$ \\
\hline
\end{tabular}

Fonte: Elaborado pelos autores

Apesar de não termos apresentado todas as produções escritas geradas em grupos e/ou individualmente, o processo de avaliação contínua empregado pela professorapesquisadora no decorrer do desenvolvimento das atividades dos alunos, permitiu inferir que nenhum grupo destoou efetivamente dos demais quanto ao objetivo e resolução das tarefas propostas. Quando uma ou outra etapa de resolução se apresentava inconsistente com o problema proposto, o próprio grupo em parceria ou não com a professorapesquisadora, estabelecia discussões em busca de um consenso e validação das respostas obtidas nas atividades desenvolvidas.

\section{Considerações finais}

No decorrer da resolução das 3 tarefas propostas, as etapas previstas na metodologia de Ensino-Aprendizagem-Avaliação através da Resolução de Problemas não foram seguidas em uma ordem hierárquica. A leitura coletiva não foi a etapa que se destacou, pois apesar das regras propostas para o exercício da comunicação, os alunos em seus respectivos grupos, preferiram eleger um relator para cada um dos grupos.

A plenária ganhou grande destaque, até mesmo sob o olhar dos alunos, pois foi o momento que através da exposição de suas ideias puderam verificar as incompletudes ou erros na resolução. Na busca do consenso houve a necessidade de aprender a ouvir, de 
ser ouvido, respeitar as colocações dos demais envolvidos, argumentar e trabalhar em conjunto para a constatação de um novo aprendizado. Por fim, a formalização do conteúdo confirmou e complementou as apreensões dos alunos, construindo as definições e conceitos geométricos pretendidos, no caso, o circuncentro como um dos pontos notáveis do triângulo.

Neste processo também ocorreram entraves para a continuidade do desenvolvimento da resolução das tarefas propostas. Destaca-se a necessidade de aprimorar o vocabulário geométrico dos alunos, à medida que os alunos perguntaram a respeito de algumas palavras e foram incentivados a pesquisar no material disponibilizado (internet, apostila, dicionário).

Outra dificuldade constatada foi a questão de explanação através da escrita sobre um conteúdo apreendido. A maior parte dos alunos apresentou limitações nesse momento: uns por ter dificuldade de se expressar na redação das respostas e argumentações e outros por indisposição. Foi de grande importância a postura mediadora da professorapesquisadora para que os estudantes compreendessem a importância da linguagem matemática escrita em aulas de matemática, disciplina que culturalmente é caracterizada como a ciência dos números e formas.

Para a professora-pesquisadora o processo de formulação de problemas foi também uma atividade desafiadora, pois com as demandas educacionais vigentes, a autoria de propostas de tarefas fica frequentemente a cargo dos autores dos mais diversos materiais didáticos disponíveis nos diferentes contextos escolares.

\section{Referências}

DUTENHEFNER, F.; CADAR, L. Encontros de geometria: parte 1. Rio de Janeiro: IMPA/OBMEP, 2015.

GALERA, S.I.N. Ensino-Aprendizagem-Avaliação: O circuncentro nas tarefas via resolução de problemas. 116f. Dissertação (Mestrado Profissional em Matemática em Rede Nacional) - Centro de Ciências Exatas e de Tecnologia, Universidade Federal de São Carlos, Sorocaba, 2018. Disponível em:

https://repositorio.ufscar.br/bitstream/handle/ufscar/10629/DISSERTA\%c3\%87\%c3\%83O \%20PARA\%20Reposit\%c3\%b3rio.pdf?sequence=1\&isAllowed=y

NACARATO, A.M. et al. Modalidades de pesquisas em educação matemática: um mapeamento de estudos qualitativos do GT-19 da Anped. In: REUNIÃO ANUAL DA ASSOCIAÇÃO NACIONAL DE PÓS-GRADUAÇÃO E PESQUISA EM EDUCAÇÃO, 28., 
2005, Caxambu. Anais... 19p. Caxambu, 2005. Disponível em:

http://docplayer.com.br/8989953-Modalidadades-de-pesquisas-em-educacao-matematicaum-mapeamento-de-estudos-qualitativos.html. Acesso em: 14 set.2021.

ONUCHIC, L.R. Ensino-Aprendizagem de Matemática através da resolução de problemas. In: BICUDO, M.A.V. (org). Pesquisa em Educação Matemática: Concepções \& Perspectiva. São Paulo, SP: Editora UNESP, 1999, p.199-220.

ONUCHIC, L. R.; ALLEVATO, N. S. G. Formação de Professores - Mudanças Urgentes na Licenciatura em Matemática. In: FROTA, M. C. R.; NASSE, L. (Org). Educação Matemática no Ensino Superior: pesquisas e debates. Recife: SBEM, 2009, 169-187.

SÃO PAULO. Secretaria da Educação. Currículo do Estado de São Paulo: Matemática e suas tecnologias - Ensino Fundamental (Ciclo II) e Ensino Médio. Coordenação de área: Nilson José Machado. 1를. ed. atual. São Paulo, SEE, 2012. 72p.

SÃO PAULO. Secretaria da Educação do Estado. Material de apoio ao Currículo do Estado de São Paulo - Caderno do Professor: 60 ano do Ensino Fundamental, Matemática. São Paulo: SEE, 2014-2017, v.1.

SÃO PAULO. Secretaria da Educação do Estado. Material de apoio ao Currículo do Estado de São Paulo - Caderno do Professor: 60 ano do Ensino Fundamental, Matemática. São Paulo: SEE, 2014-2017, v.2.

SÃO PAULO. Secretaria da Educação do Estado. Material de apoio ao Currículo do Estado de São Paulo - Caderno do Professor: $7^{\circ}$ ano do Ensino Fundamental, Matemática. São Paulo: SEE, 2014-2017, v.1.

SÃO PAULO. Secretaria da Educação do Estado. Material de apoio ao Currículo do Estado de São Paulo - Caderno do Professor: 8 ano do Ensino Fundamental, Matemática. São Paulo: SEE, 2014-2017, v.2.

\section{NOTAS}

IDENTIFICAÇÂO DO TEXTO: O presente texto é um recorte da pesquisa "Ensino-Aprendizagem-Avaliação: O circuncentro nas tarefas via resolução de problemas", dissertação de Mestrado Profissional em Matemática em Rede Nacional (Profmat) apresentado na UFSCar-campus Sorocaba, em 31/08/2018, elaborada sob orientação do Professor Dr. Paulo César Oliveira.

\section{IDENTIFICAÇÃO DE AUTORIA}

Sandra Iris Naveiro Galera. Discente do Programa de Mestrado Profissional em Matemática em Rede Nacional (PROFMAT). Universidade Federal de São Carlos (UFSCar), SP, Brasil.

E-mail: sandranave@hotmail.com

(D) https://orcid.org/0000-0003-4493-6700

Paulo César Oliveira. Doutor. Docente do Programa de Mestrado Profissional em Matemática em Rede Nacional (PROFMAT). Universidade Federal de São Carlos (UFSCar), SP, Brasil.

E-mail: paulooliveira@ufscar,br

(iD) https://orcid.org/0000-0003-2514-904X 


\section{AGRADECIMENTOS}

Os autores agradecem aos idealizadores do Profmat e ao corpo docente da Universidade Federal de São Carlos (UFSCar).

\section{FINANCIAMENTO}

O presente trabalho foi realizado com apoio da Coordenação de Aperfeiçoamento de Pessoal de Nível Superior - Brasil (CAPES) - Código de Financiamento 001.

\section{CONSENTIMENTO DE USO DE IMAGEM}

Não se aplica.

\section{APROVAÇÃO DE COMITÊ DE ÉTICA EM PESQUISA}

Não se aplica.

\section{LICENÇA DE USO}

Autores mantêm os direitos autorais e concedem à revista ENSIN@ UFMS - ISSN 2525-7056 o direito de primeira publicação, com o trabalho simultaneamente licenciado sob a Licença Creative Commons Attribution (CC BY-NC-SA 4.0), que permite compartilhar e adaptar o trabalho, para fins não comerciais, reconhecendo a autoria do texto e publicação inicial neste periódico, desde que adotem a mesma licença, compartilhar igual.

\section{EDITORES}

Patricia Helena Mirandola Garcia, Eugenia Brunilda Opazo Uribe, Gerson dos Santos Farias.

\section{HISTÓRICO}

Recebido em: 15/09/2021 - Aprovado em: 23/10/2021 - Publicado em: 15/12/2021.

\section{COMO CITAR}

GALERA, S. I. N; OLIVEIRA, P. C. Pontos Notáveis do Triângulo: Um Estudo através da Resolução de Problemas. Revista ENSIN@ UFMS, Três Lagoas, v. 2, número especial, p. 119-142. 2021. 